\title{
Expressions of Livin and Smac and their correlation in endometriosis
}

\author{
Ping Zhu, Shuna Shen* \\ Department of Obstetrics and Gynecology, Baogang Hospital, Baotou, Inner Mongolia, China
}

Received: January 8, 2018

DOI: $10.14725 /$ dcc.v5n1p9

\author{
Accepted: February 16, 2018 \\ Online Published: March 10, 2018 \\ URL: http://dx.doi.org/10.14725/dcc.v5n1p9
}

\begin{abstract}
Objective: To explore the expression of Livin (a new member of inhibitors of apoptosis proteins) and second mitochondriaderived activator of caspases (Smac) in endometriosis (EMs), and the relationship of Livin and Smac with menstrual cycle and clinical staging of EMs, as well as correlation analysis.

Methods: 60 cases of patients, who were given laparoscopic surgery or laparotomy operation due to EMs (confirmed by postoperative pathological examinations) in Department of Obstetrics and Gynecology of the Third Affiliated Hospital of Inner Mongolia Medical College from October 2010 to April 2012, were selected and included into the study group. The study group was subdivided into the eutopic group and the ectopic group, each of which contained 30 cases (16 cases for the proliferative phase, 14 cases for the secretory phase). 30 samples of normal endometrial tissues were chosen as the control group. Immunohistochemical method (SP) was used to determine the expression of Livin and Smac proteins in each group, with statistical analysis conducted to the results.

Results: The expression of Livin in eutopic and ectopic endometrial tissues in EMs was significantly higher than that in normal endometrial tissues in the control group, and the difference was statistically significant $\left(\chi^{2}=12.510, p<.05\right)$; The expression of Smac in eutopic and ectopic endometrial tissues in EMs was significantly lower than that in normal endometrial tissues in the control group, and the difference was statistically significant $\left(\chi^{2}=19.530, p<.05\right)$. The expression of Livin and Smac in the eutopic and the ectopic endometrial tissues in EMs had no correlation to clinical staging $\left(\chi^{2}=0.741\right.$ and $\chi^{2}=0.002$ respectively, all $p>.05$ ); In the eutopic and the ectopic endometrial tissues in EMs, the expression of Livin was negatively correlated to the expression of Smac $\left(r_{s}=-0.933\right.$ and $r_{s}=-0.867$ respectively, all $\left.p<.05\right)$.

Conclusions: The high expression of Livin and the low expression of Smac enhance the abilities of hyperplasia and antiapoptosis of ectopic endometrial cells, which leads to the occurrence and development of EMs.
\end{abstract}

Key Words: Endometriosis, Inhibitor of apoptosis proteins, Second mitochondrial activator of caspases, Immunohistochemistry

Endometriosis (EMs) refers to a condition in which endometrial tissues that normally cover the inside of the uterus (and myometrium) grow outside of it. This type of tissues mostly invades the ovaries, and seriously harms women's health. ${ }^{[1]}$ Livin, a new member of inhibitors of apoptosis proteins (IAPs), plays a role in the inhibition of antiapopto- sis through various ways; ${ }^{[2]}$ and second mitochondrial activator of caspases (Smac) can play a part in the pro-apoptosis by preventing the action of IAPs. ${ }^{[3]}$ This study was intended to perform a correlation analysis to the expression of Livin and Smac in EMs and their relationships with the menstrual cycle and clinical staging of EMs, in order to explore the

\footnotetext{
*Correspondence: Shuna Shen; E-mail: shunashen@126.com; Address: Department of Obstetrics and Gynecology, Baogang Hospital, Baotou, Inner Mongolia, China.
} 
relationship of the two factors with the occurrence and development of EMs and provide a new theoretical basis for clinical diagnosis, treatment and prognostic evaluation of EMs.

\section{Data and methods}

\subsection{Research objects}

60 cases of patients, who were given laparoscopic surgery or laparotomy operation due to EMs (confirmed by postoperative pathological examinations) in Department of Obstetrics and Gynecology of the Third Affiliated Hospital of Inner Mongolia Medical College from October 2010 to April 2012, were selected and included into the study group, which contained 30 cases of eutopic endometrial tissues and 30 cases of ectopic endometrial tissues (16 cases for the proliferative phase, 14 cases for the secretory phase). The study group was subdivided into the ectopic group and the eutopic group. Ectopic group: patients, aged from 21 to 52 years, can be classified as follows in conformity with clinical staging standards established by American Fertility Association (R-AFS) in 1985: 14 cases for I-II, 16 cases for III-IV. Eutopic group: eutopic endometria were taken from EMs patients by diagnostic curettage or hysterectomy. Combined with the menstrual history, endometrial staging is based on the characteristics of endometrium morphology in different stages to make judgments. 30 cases of patients, randomly selected during the same period and given hysterectomy due to cervical lesions without adenomyosis and EMs, were included in the control group, in which endometria taken from these patients were verified as normal endometrial tissues by postoperative pathological examinations.

All of the subjects were of complete clinicopathological data, without oral steroid hormones taken in 6 months before surgery, with no IUD placed, no lesions in the endometrium, regular menstrual cycle and no history of endocrine diseases.

\subsection{Experimental methods}

The immunohistochemical SP method was used to carry out the experiment. The average percentage of positive cells in each field was counted as the percentage of positive cells in the section, and then scored as follows: the percentage of positive cells more than $75 \%$ was $4,51 \%-75 \%$ for $3,26 \%$ $50 \%$ for $2,5 \%-25 \%$ for 1 , less than $5 \%$ for 0 ; The positive intensity is based on the chromogenic reaction of most cells: dark brownish-yellow for 3 points; brownish-yellow for 2 points; light brownish-yellow for 1 point; no coloring or slight coloring for 0 point. The results were determined through comprehensive analysis: the product $(>3)$ obtained by multiplying the percentage of positive cells and the positive intensity together, can be used as the positive standard.

\subsection{Statistical methods}

Excel 2000 was used to set up a database, and SPSS 16.0 software package was applied to the statistical analysis. The comparison of measurement data between two groups was made by use of $\chi^{2}$ test, and the correlation test was performed by use of Spearman's correlation analysis. The difference $(p<.05)$ was of statistical significance.

\section{Results}

\subsection{The gene expression of Livin}

Livin was mainly expressed in the cytoplasm of endometrial epithelial cells, almost with no expression in endometrial vessels (see Figure 1).

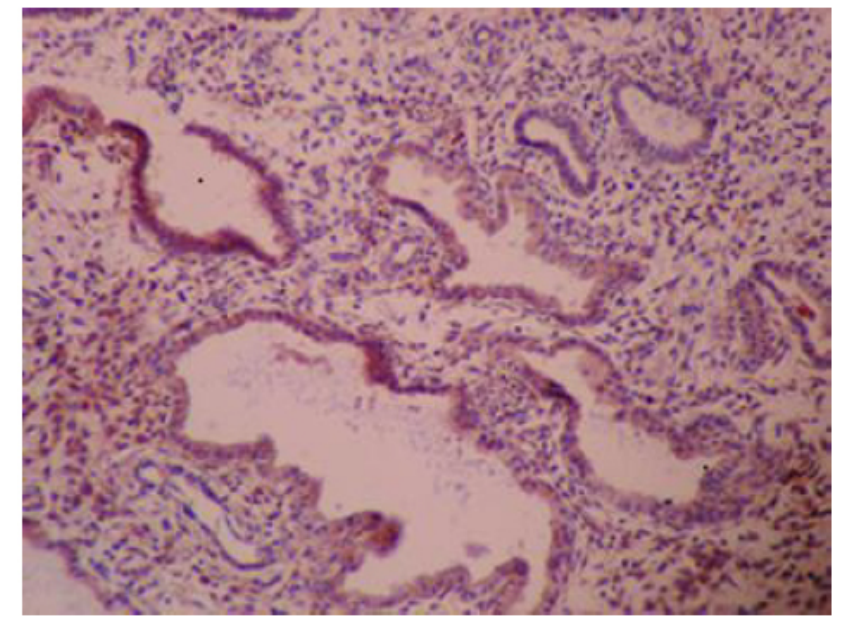

Figure 1: The expression of Livin in eutopic endometria $(100 \times)$

The difference in the positive expression of Livin in the control group, eutopic group and ectopic group was of statistical significance $\left(\chi^{2}=12.510, p<.05\right)$. The positive expression of Livin in ectopic and eutopic groups was significantly higher than that in the control group $\left(\chi^{2}=11.280\right.$ and $\chi^{2}=$ 6.690 respectively, all $p<.05$ ); The difference in the positive expression of Livin in eutopic and ectopic groups was of no statistical significance $\left(\chi^{2}=0.693, p>.05\right.$, see Table 1). The difference in the positive expression of Livin between the proliferative phase and the secretory phase was of no statistical significance, no matter in the study group or the control group (all $p>.05$, see Table 2). 
Table 1: Comparison in the expression of Livin and Smac among different groups

\begin{tabular}{|c|c|c|c|c|c|}
\hline \multirow{2}{*}{ Group } & \multirow{2}{*}{ Cases (n) } & \multicolumn{2}{|c|}{ Livin } & \multicolumn{2}{|c|}{ Smac } \\
\hline & & + & - & + & - \\
\hline Control Group & 30 & $9(30.0)$ & $21(70.0)$ & $22(73.3)$ & $8(26.7)$ \\
\hline Eutopic Group & 30 & $19(63.3)$ & $11(36.7)$ & $13(43.3)$ & $17(56.7)$ \\
\hline Ectopic Group & 30 & $22(73.3)$ & $8(16.7)$ & $5(16.7)$ & $25(83.3)$ \\
\hline
\end{tabular}

Table 2: Comparison in the expression of Livin and Smac in the proliferative and secretory phase among different groups

\begin{tabular}{|c|c|c|c|c|c|c|c|c|c|c|}
\hline \multirow{2}{*}{ Group } & \multirow{2}{*}{ Staging } & \multirow{2}{*}{ Cases (n) } & \multicolumn{2}{|c|}{ Livin } & \multirow{2}{*}{$\chi^{2}$} & \multirow{2}{*}{$p$} & \multicolumn{2}{|c|}{ Smac } & \multirow{2}{*}{$\chi^{2}$} & \multirow{2}{*}{$p$} \\
\hline & & & + & - & & & + & - & & \\
\hline Control & Proliferative Phase & 16 & $5(31.3)$ & $11(68.7)$ & \multirow{2}{*}{0.026} & \multirow{2}{*}{$>.05$} & $9(56.3)$ & 7 (43.7) & \multirow{2}{*}{5.117} & \multirow{2}{*}{$<.05$} \\
\hline Group & Secretory Phase & 14 & 4 (28.6) & $10(71.4)$ & & & $13(92.9)$ & $1(7.1)$ & & \\
\hline Eutopic & Proliferative Phase & 16 & $10(62.5)$ & $6(37.5)$ & \multirow{2}{*}{0.01} & \multirow{2}{*}{$>.05$} & $7(43.8)$ & $9(56.2)$ & \multirow{2}{*}{0.002} & \multirow{2}{*}{$>.05$} \\
\hline Group & Secretory Phase & 14 & $9(64.3)$ & $5(35.7)$ & & & $6(42.9)$ & $8(57.1)$ & & \\
\hline Ectopic & Proliferative Phase & 16 & $11(68.8)$ & $5(31.2)$ & \multirow{2}{*}{0.368} & \multirow{2}{*}{$>.05$} & $3(18.8)$ & $13(81.2)$ & \multirow{2}{*}{0.107} & \multirow{2}{*}{$>.05$} \\
\hline Group & Secretory Phase & 14 & $11(78.6)$ & $3(21.4)$ & & & $2(14.3)$ & $12(85.7)$ & & \\
\hline
\end{tabular}

\subsection{The gene expression of Smac}

Smac was mainly expressed in the cytoplasm of endometrial glandular cells, almost with no expression in endometrial vessels (see Figure 2).

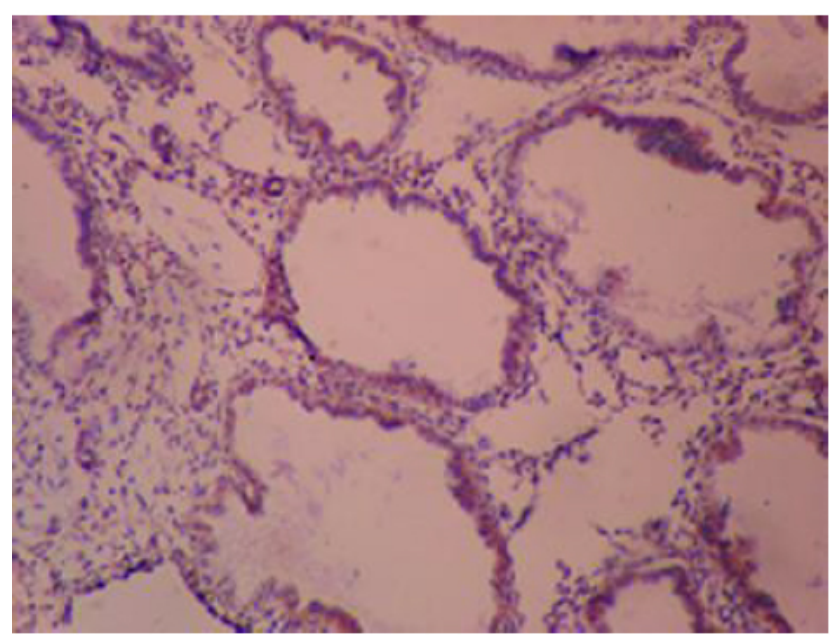

Figure 2: The expression of Livin in eutopic endometria $(100 \times)$
The difference in the positive expression of Smac in the control group, eutopic group and ectopic group was of statistical significance $\left(\chi^{2}=19.530, p<.05\right)$. The positive expression of Smac in ectopic and eutopic groups was significantly lower than that in the control group $\left(\chi^{2}=19.461\right.$ and $\chi^{2}=$ 5.554 respectively, all $p<.05$ ); The difference in the positive expression of Smac in eutopic and ectopic groups was of statistical significance $\left(\chi^{2}=5.079, p<.05\right.$, see Table 1 ). The difference in the positive expression of Smac in the proliferative phase and the secretory phase was of no statistical significance, both in the eutopic group and the ectopic group (all $p>.05$ ). However, in the control group, the positive expression in the secretory phase was higher than that in the proliferative phase, and the difference was of statistical significance $(p<.05$, see Table 2$)$.

\subsection{The relationship between the expression of Livin and Smac and the clinical staging of EMs}

In the eutopic group, the difference of Livin expression in stage I-II and the stage III-IV was of no statistical significance $\left(\chi^{2}=0.741, p>.05\right)$; The difference of Smac expression in both stages was of no statistical significance $\left(\chi^{2}=\right.$ $0.002, p>.05$, see Table 3).

Table 3: Relationship of Livin and Smac expressions with clinical staging of EMs

\begin{tabular}{|c|c|c|c|c|c|}
\hline \multirow{2}{*}{ Group } & \multirow{2}{*}{ Cases (n) } & \multicolumn{2}{|c|}{ Livin } & \multicolumn{2}{|c|}{ Smac } \\
\hline & & + & - & + & - \\
\hline I-II & 14 & $10(71.4)$ & 4 (28.6) & $6(42.9)$ & $8(57.1)$ \\
\hline III- IV & 16 & $9(56.3)$ & $7(43.7)$ & $7(77.8)$ & $9(22.2)$ \\
\hline
\end{tabular}




\subsection{The correlation of Livin to Smac in EMs}

Spearman's correlation analysis showed that, in the eutopic group and the ectopic group, Livin was negatively correlated to $\operatorname{Smac}\left(r_{s}=-0.933\right.$ and $r_{s}=-0.867$ respectively, all $p<.05)$.

\section{Discussion}

\subsection{The relationship between the gene of Livin and EMs}

Livin, a new member of IAPs, was discovered in 2000. ${ }^{[4]}$ Located at q13.3 on human chromosome 20, it contains seven exons and six introns, with a total length of about $4.6 \mathrm{~kb}$. The carboxyl terminal of Livin protein contains a RING finger structure consisting of one histidine (His) and 7 cysteines (Cys) with two zinc ions bound; The Nterminal contains one BIR domain, which is a novel zinc finger structure, including 70 highly conserved amino acids. The BIR domain is probably the anti-apoptotic site of Livin gene. In recent years, studies have found that there exists apoptosis in endometria, and its periodic cell proliferation and shedding can be achieved through the imbalance of cell apoptosis and proliferation. This periodic change is regulated by the level of pro-apoptotic gene. ${ }^{[5]}$ Studies have shown that Livin can inhibit apoptosis by the following three pathways: $^{[6,7]}$ (1) Livin can inhibit the activity of cysteinecontaining aspartate-specific protease-3 (Caspase-3), simultaneously bind unactivated Caspase-9, activated Caspase-9 and Caspase-9 precursor proteins to block their sequential cleavage and activation and to block the positive feedback activation of Caspase-3 to Caspase-9 precursors, resulting in anti-apoptotic effect; (2) Livin can bind TAB1 (TAK1 binding protein) to activate TAK1 (TGF- $\beta$ activated kinase), and TAB 1 is the coactivator of TAK1, with the effect in promoting the activation of mitogen-activated protein kinase/cJun N-terminal kinase-1 (JNK1), so that JNK1 is activated through the TAB1/TAK1 pathway to counteract cell apoptosis; (3) Livin can prevent cell apoptosis caused by cellular DNA damage resulted from chemotherapy drugs. The results of this study indicated that the positive expression of Livin in ectopic and eutopic endometria of EMs significantly exceeded that in normal endometria, and the expression of Livin in endometria of the first two groups was not statistically significant. No matter the study group or the normal control group, the positive expression of Livin was not correlated to menstrual cycle and clinical staging. In recent years, there have been few reports about the expression of Livin in normal endometria and EMs at home and abroad. Wang CF et al. ${ }^{[8]}$ utilized an immunohistochemical method to detect the expression of Livin in 30 cases of normal endometrial tissues and 30 cases of eutopic and ectopic endometrial tissues in EMs. It was indicated that the expression of Livin in the normal control group was obvi- ously lower than that in the eutopic and ectopic groups. The difference was not statistically significant, with the experimental results supporting the results of this study. Currently, Livin has been found to be abnormally expressed in a variety of tumor cells and closely related to tumorigenesis. Livin is rarely expressed in normal tissues but can be highly expressed in tissues in malignant tumors such as lung cancer, breast cancer, digestive system malignancy, bladder cancer, leukemia and lymphoma etc.

\subsection{The relationship between Smac gene and EMs}

Smac/DIABLO protein, i.e., second mitochondria-derived activator of caspases/direct IAP binding protein with low PI, was isolated from HeLa cell experiments made in 2000. ${ }^{[9]}$ Human Smac gene, located on the long arm of chromosome 12 , contains 7 exons, with its mRNA about $1.5 \mathrm{~kb}$ in full length. It can encode 239 amino acids, where 55 amino acids at the N-terminal are called mitochondrial target sequence (MTS), the function of which is to ensure that unprocessed Smac proteins shall be located on the mitochondria, whereas MTS is decomposed by the mitochondrial signal peptide after Smac is transferred into the mitochondria. Eventually, unprocessed Smac proteins containing 184 amino acid residues are generated, with the apoptotic activity acquired simultaneously. The mature Smac protein exists in the intermembrane space of the mitochondria as a dimer and is released into the cytoplasm when it is affected by apoptosis-inducing factors such as anticancer drugs, chemical or physical apoptotic signals, etc. ${ }^{[3]}$ The mechanism of Smac in promoting cell apoptosis is as follows: ${ }^{[10,11]}$ (1) The N-terminal tetrapeptide of Smac shows obvious homology to Caspase-9 N-terminal tetrapeptide, and it releases the inhibitory effect on Caspase-9 by competition, activates cascade reactions of Caspases and promotes the progress of cell apoptosis; (2) Smac can promote the decomposition of pro-caspase-3, whose product p24 is successfully cleaved to generate product $\mathrm{p} 20 / \mathrm{p} 17$, the latter can constitute the activated caspase- 3 together with $\mathrm{p} 12$, and the activated caspase- 3 can activate the caspase- 9 zymogens in turn, forming a positive feedback pathway to play a role in promoting cell apoptosis; (3) it was found by Kim (2005) that Smac may also promote cell apoptosis in a Caspaseindependent manner, which was speculated to be more efficient than the caspase-dependent way. The results of this study showed that the positive expression of Smac in normal endometria, eutopic endometria and ectopic endometria of EMs was significantly decreased, and the difference among groups was of statistical significance $(p<.05)$. The positive expression of Smac in eutopic and ectopic endometria in EMs was not correlated to menstrual cycle and clinical staging (all $p>.05$ ). However, in normal endometria, the positive expression in the secretory phase was higher than that in the proliferative phase in the menstrual cycle $(p<.05)$. It is consistent with the theory that endometrial 
apoptosis is exacerbated in the secretory phase to promote the shedding of endometria. ${ }^{[12]}$

\subsection{The relationship between Livin gene and Smac gene}

The results of this study showed that Livin was negatively correlated to Smac in EMs. Both Livin and Smac proteins may play a role in the occurrence of EMs by regulating cell apoptosis, they may be an important part in the occurrence of EMs, ${ }^{[8]}$ and their synergistic effect may weaken the pro-apoptotic ability of the ectopic endometrial cells and enhance the anti-apoptotic ability, causing hyperplasia of endometrial cells in other parts out of control. Ectopic and eutopic endometrial cells in patients with EMs are of a

\section{References}

[1] Johnson NP, Hummelshoj L. Consensus on current management of endometriosis. Hum Reprod. 2013; 28(6): 1552-1568. PMid: 23528916. https://doi.org/10.1093/humrep/det050

[2] Chung CY, Park YL, Kim N, et al. Expression and prognosticsignificance of Livin in gastric cancer. Oncol Rep. 2013; 30(5): 25202528. PMid: 24008725. https://doi.org/10.3892/or. 2013. 2724

[3] Bake V, Roesler S, Eckhardt I, et al. Synergistic interaction of Smac mimetic and IFN $\alpha$ to trigger apoptosis in acute myeloid leukemia cells. Cancer Letters. 2014; 35(52): 78-79.

[4] Ding ZY, Liu GH, Olsson B, et al. Upregulation of the antiapoptotic factor Livin contributes to cisplatin resistance incolon cancer cells. Tumour Biol. 2013; 34(2): 683-693. PMid: 23188704. https://doi.org/10.1007/s13277-012-0596-8

[5] Li XL, Jiao YS, Wang YL, et al. Expression and Significance of Livin and Smac in Endometriosis. Journal of China Medical University. 2010; 39(5): 362-365.

[6] Lin H, Lin D, Xiong X. Differential expression of Livin, caspase3 , and second mitochondria-derived activator of caspasesin chronic rhinosinusitis with nasal polyps. Otolaryng Head Neck. 2014; low apoptosis rate but a high proliferation rate. Normal endometrial cells with biological activities, flow upstream with menstruation into the abdominopelvic cavity. These cells with a low apoptosis rate continue to survive and implant inside the pelvic, causing ectopic lesions to occur and develop where they are located. RNAi technology is a newly developed molecular biology technology. It can be combined with specific mRNA to disintegrate the target gene. The application of this technology silencing the specific gene, provides a new development direction for the gene therapy of diseases.

\section{Conflicts of Interest Disclosure}

The authors have no conflicts of interest related to this article.

151(6): 1067-1072. PMid: 25238746. https://doi.org/10. 1177/0194599814551142

[7] Ma YQ, Wang L, Ma H, et al. The expression of FAF1 and Livin proteins in gastric carcinoma and its clinical significance. Journal of Shanxi Medical University. 2014; 45(3): 173-176, 247.

[8] Zhao Q, Bian AP, Wang CF. Expression of Livin and Smac protein in endometrium of endometriosis patients. Journal of Zhengzhou University (Medical Sciences). 2011; 46(2): 228-230.

[9] Hu W, Wang F, Tang J, et al. Pro-apoptotic protein, Smac, mediates apoptosis in cisplatin-resistant ovarian cancer cells when treated with the anti-tumor agent, at 101. J Biol Chem. 2012; 287(1): 68-80. PMid: 22052903. https://doi.org/10.1016/j.str. 2011.05 .013

[10] Laukens B, Jennewein C, Schenk B, et al. Smac Mimetic Bypasses Apoptosis Resistance in FADD-or Caspase-8 - Deficient Cells by Priming for Tumor Necrosis Factor $\alpha$-Induced Necroptosis. Neoplasia. 2011; 13(10): 370-371. https://doi.org/10.1593/neo. 11610

[11] Fulda S. Smac mimetics as IAP antagonists. Seminars in Cell and Developmental Biology. 2014; 23(6): 1338-1339.

[12] Zhang L, Shi B, Ren XP, et al. Effect of XIAP, XAF1 and TNF- $\alpha$ in endometriosis. Chinese Journal of Family Planning. 2012; 20(9): 604-607. 